\title{
Application of Intestinal Epithelial Cells Differentiated from Human Induced Pluripotent Stem Cells for Studies of Prodrug Hydrolysis and Drug Absorption in the Small Intestine ${ }^{\mathbb{S}}$
}

\author{
(1)Takanori Akazawa, Shinpei Yoshida, Shuichi Ohnishi, Takushi Kanazu, Makoto Kawai, \\ and Koji Takahashi
}

\begin{abstract}
Research Laboratory for Development (T.A., S.Y., S.O., T.K.), Medicinal Chemistry Research Laboratory (M.K.), and Drug Discovery and Disease Research Laboratory (K.T.), Shionogi \& Co., Ltd, Toyonaka, Osaka, Japan
\end{abstract}

Received June 29, 2018; accepted August 17, 2018

\begin{abstract}
Cell models to investigate intestinal absorption functions, such as those of transporters and metabolic enzymes, are essential for oral drug discovery and development. The purpose of this study was to generate intestinal epithelial cells from human induced pluripotent stem cells (hiPSC-IECs) and then clarify whether the functions of hydrolase and transporters in them reflect oral drug absorption in the small intestine. The hiPSC-IECs showed the transport activities of P-glycoprotein (P-gp), breast cancer resistance protein (BCRP), and peptide transporter 1 (PEPT1), revealed by using their probe substrates $\left(\left[{ }^{3} \mathrm{H}\right]\right.$ digoxin, sulfasalazine, and $\left[{ }^{14} \mathrm{C}\right]$ glycylsarcosine), and the metabolic activities of CYP3A4, CES2, and CES1, which were clarified using their probe substrates (midazolam, irinotecan, and temocapril). The intrinsic clearance by hydrolysis of six ester
\end{abstract}

prodrugs into the active form in hiPSC-IECs was correlated with the plasma exposure ( $C_{\text {max }}, A U C$, and bioavailability) of the active form after oral administration of these prodrugs to rats. Also, the permeability coefficients of $\mathbf{1 4}$ drugs, containing two substrates of P-gp (doxorubicin and $\left[{ }^{3} \mathrm{H}\right]$ digoxin), one substrate of BCRP (sulfasalazine), and 11 nonsubstrates of transporters (ganciclovir, $\left[{ }^{14} \mathrm{C}\right]$ mannitol, famotidine, sulpiride, atenolol, furosemide, ranitidine, hydrochlorothiazide, acetaminophen, propranolol, and antipyrine) in hiPSC-IECs were correlated with their values of the fraction of intestinal absorption (Fa) in human clinical studies. These findings suggest that hiPSC-IECs would be a useful cell model to investigate the hydrolysis of ester prodrugs and to predict drug absorption in the small intestine.

\section{Introduction}

Successful prediction of human intestinal absorption can help minimize the number of drug candidates dropped owing to pharmacokinetic problems during human clinical phase studies of oral drug discovery and development. Oral drug absorption is influenced by transporters and metabolic enzymes expressed in intestinal epithelial cells. P-glycoprotein (P-gp) and breast cancer resistance protein (BCRP) are important efflux transporters in the small intestine, and there is some clinical relevance in the oral absorption of substrates of these transporters being restricted by efflux transport via these transporters [including such substrates as digoxin, fexofenadine, aliskiren, dabigatran (P-gp substrates) and sulfasalazine, atorvastatin, and rosuvastatin (BCRP substrates)] (Simpson and Jarvis, 2000; Fenner et al., 2009; Keskitalo et al., 2009; Tapaninen et al., 2011; Kusuhara

https://doi.org/10.1124/dmd.118.083246.

S This article has supplemental material available at dmd.aspetjournals.org. et al., 2012; Delavenne et al., 2013). Peptide transporter 1 (PEPT1) is also involved in transport from the intestinal lumen into epithelial cells of $\beta$-lactam antibiotics and ACE inhibitors (Rubio-Aliaga and Daniel, 2008). In addition to transporters, CYP3A4, of all P450 isoforms, is the most abundantly expressed in human small intestine and contributes to the intestinal first-pass metabolism of many substrates, such as midazolam and nifedipine (Rashid et al., 1995; Paine et al., 1996, 2006; Gröer et al., 2014; Miyauchi et al., 2016; Akazawa et al., 2018). CES2 is also an important hydrolytic enzyme in the small intestine involved in converting an ester prodrug, such as irinotecan, into its active form (Humerickhouse et al., 2000). To properly predict human intestinal drug absorption from in vitro assessment, a comprehensive cell model of the functions of transporters and metabolic enzymes in human small intestine is desirable.

Caco-2 cells, a human colon carcinoma cell line, have been widely used to predict the fraction of intestinal absorption $(F a)$ in humans during drug discovery and development. However, it is difficult to investigate the intestinal first-pass metabolism, because Caco- 2 cells do not express

ABBREVIATIONS: A-83-01, 3-(6-Methyl-2-pyridinyl)-N-phenyl-4-(4-quinolinyl)-1H-pyrazole-1-carbothioamide; AUC, area under the plasma concentrationtime curve; $B A$, bioavailability; BCRP, breast cancer resistance protein; BNPP, bis-p-nitrophenyl phosphate; CDX2, caudal type homeobox 2; CES, carboxylesterase; CHGA, chromogranin A; DE, definitive endoderm; EGF, epidermal growth factor; FOXA2, forkhead box protein A2; GAPDH, glyceraldehyde-3-phosphate dehydrogenase; GATA4, GATA binding protein 4; HG, hindgut; hiPSC-IECs, human induced pluripotent stem cellderived intestinal epithelial cells; hiPSCs, human induced pluripotent stem cells; IEC, intestinal epithelial cells; ISX, intestine specific homeobox; KO143, 3 $\beta$-(3-tert-Butoxy-3-oxopropyl)-2,3,6,7,12,12a $\alpha$-hexahydro-6 $\beta$-isobutyl-9-methoxypyrazino[1',2':1,6]pyrido[3,4-b]indole-1,4-dione; LC-MS/MS, liquid chromatography-tandem mass spectrometry; LGR5, leucine rich repeat containing G protein-coupled receptor 5; LYZ, lysozyme; MUC2, mucin 2; OCT3/4, octamer-binding transcription factor 3/4; PEPT1, peptide transporter 1; P-gp, P-glycoprotein; qPCR, quantitative polymerase chain reaction; SI, sucrase-isomaltase; SOX, SRY (sex-determining region Y)-box; SN-38, 7-ethyl-10-hydroxy-camptothecin; TEER, transepithelial electrical resistance; TFF3, trefoil factor 3; UGT, UDP-glucuronosyltransferase; VIL, villin-1. 
metabolic enzymes such as CYP3A4 (Prueksaritanont et al., 1996; Taipalensuu et al., 2001). Furthermore, Caco-2 cells also show different expression patterns of carboxylesterase (CES) isozymes compared with those in the human small intestine; CES2 is more highly expressed than CES1 in human small intestine, whereas CES1 is more highly expressed than CES2 in Caco-2 cells (Imai et al., 2005). Thus, hydrolysis of CES1 substrates, such as temocapril and dabigatran etexilate, has been reported to be overestimated in Caco-2 cells compared with human small intestine (Imai et al., 2005; Ishiguro et al., 2014). These findings show the risk of mistaken prediction of oral absorption of prodrugs.

In recent years, several researchers have succeeded in generating intestinal epithelial cells from human induced pluripotent stem cells (hiPSCs) (Spence et al., 2011; Kauffman et al., 2013; Ogaki et al., 2013; Forbester et al., 2015; Iwao et al., 2015; Ozawa et al., 2015; Uchida et al., 2017). Human induced pluripotent stem cell-derived intestinal epithelial cells (hiPSC-IECs) would be a good tool to predict the absorption of oral drugs in humans, because they are reported to have the functions of transporters, such as BCRP and PEPT1, as well as of metabolic enzymes, such as CYP3A4 and CES2 (Iwao et al., 2015; Ogaki et al., 2015; Ozawa et al., 2015; Kodama et al., 2016; Kabeya et al., 2017; Uchida et al., 2017). Unlike Caco-2 cells, hiPSC-IECs show an expression pattern of CES isozymes similar to the human small intestine; CES2 is expressed at levels higher than CES1 (Kabeya et al., 2017). This suggests that hiPSC-IECs would be more useful than Caco-2 cells for investigating the intestinal hydrolysis of CES substrates, such as ester prodrugs, but it is unknown whether the hydrolysis in hiPSCIECs reflects the in vivo function of intestinal hydrolysis. In addition, Kodama et al. (2016) demonstrated that the permeabilities across hiPSC-IEC monolayers via passive diffusion were correlated with $\mathrm{Fa}$ values in humans, but it has not been clarified whether human intestinal absorption of substrates for transporters can be accurately predicted by using hiPSC-IECs.

Therefore, the purpose of this study was to generate hiPSC-IECs and to find whether the functions of hydrolase and transporters in hiPSCIECs can reflect oral drug absorption in the small intestine. First, the in vitro hydrolysis activities of ester prodrugs in hiPSC-IECs was compared with the plasma exposures $\left[C_{\text {max }}\right.$, area under the plasma concentration-time curve (AUC), and bioavailability $(B A)]$ of the active form in rats, as they are relevant to in vivo hydrolysis activities. Second, the permeabilities of 14 drugs, containing two substrates of P-gp (doxorubicin and $\left[{ }^{3} \mathrm{H}\right]$ digoxin), one substrate of BCRP (sulfasalazine), and 11 nonsubstrates of transporters (ganciclovir, $\left[{ }^{14} \mathrm{C}\right]$ mannitol, famotidine, sulpiride, atenolol, furosemide, ranitidine, hydrochlorothiazide, acetaminophen, propranolol, and antipyrine), were compared with human $\mathrm{Fa}$ values.

\section{Materials and Methods}

Materials. A human iPS cell line (TkDA3-4), established as described previously (Takayama et al., 2010), was graciously provided by Dr. Makoto Otsu (The Institute of Medical Science, The University of Tokyo, Tokyo, Japan). All studies with human iPS cells were approved by the Ethics Committee on Human Tissue and Genome Research at Shionogi \& Co., Ltd. (Toyonaka, Japan). The Caco-2 cell line was purchased from the American Type Culture Collection (Rockville, MD). Total RNAs of human adult small intestines pooled from five donors (20-61 years old) and human fetal small intestine from one donor (26 weeks of gestation) were purchased from Clonetech (Palo Alto, CA) and BioChain Institute Inc. (Newark, CA), respectively. Six ester prodrugs (prodrugs A, B , C, D, E, and F) and the active forms, candidates for anti-influenza virus agents, were in-house compounds synthesized by Shionogi \& Co., Ltd.; these prodrugs were hydrolyzed into the same active form (Supplemental Fig. S1; Supplemental Table S1). All other reagents were of the highest quality available.
Animals. Male Sprague-Dawley (SD) rats (8 weeks of age) were purchased from CLEA Japan Inc. (Osaka, Japan). Rats were maintained on a 12-hour light/dark cycle in a temperature- and humidity-controlled environment with free access to food and water. At more than 3 days before the experiment, a cannula tube was inserted into the jugular vein of each rat under ether anesthesia. All animal studies were approved by the Committee for Animal Care and Use at Shionogi \& Co., Ltd.

Cultivation of hiPSC-IEC and Caco-2 Cell Monolayers on Transwell Inserts. HiPSC-IECs were generated from hiPSCs according to the preparation methods as described in the Supplemental Data. Generated hiPSC-IECs were seeded on porous polyester membrane 24-well Transwell inserts $(0.4-\mu \mathrm{m}$ pore size and $0.33-\mathrm{cm}^{2}$ filter area) (Corning Inc., Corning, NY) coated with $0.5 \mathrm{mg} / \mathrm{ml}$ of laminin 511-E8 (iMatrix-511; Nippi, Tokyo, Japan) at a density of $3.0 \times 10^{5}$ cells $/ \mathrm{cm}^{2}$. Cells were cultured with intestinal epithelial cell (IEC) maintenance medium [Advanced DMEM/F12 (Thermo Fisher Scientific, San Jose, CA) supplemented with $500 \mathrm{ng} / \mathrm{ml}$ R-Spondin 1 (R\&D Systems, Minneapolis, MN), $100 \mathrm{ng} / \mathrm{ml}$ Noggin (R\&D Systems), $50 \mathrm{ng} / \mathrm{ml}$ epidermal growth factor (EGF; R\&D Systems), 2 mM L-glutamine (Thermo Fisher Scientific, Waltham, MA), $100 \mathrm{IU} / \mathrm{ml}$ penicillin-streptomycin (Thermo Fisher Scientific), $15 \mathrm{mM}$ HEPES (Thermo Fisher Scientific), 2\% (v/v) B27 supplement (Thermo Fisher Scientific), $1 \% \mathrm{~N} 2$ supplement (Thermo Fisher Scientific), $1 \mathrm{mM} \mathrm{N}$-acetylcysteine (MilliporeSigma, St. Louis, MO), $10 \mathrm{nM}$ human gastrin 1 (Peptide Institute, Osaka, Japan), and $500 \mathrm{nM}$ A-83-01 (Tocris, Bristol, UK)] containing $10 \mu \mathrm{M}$ Y-27632 (Fujifilm Wako Pure Chemical Ind. Ltd., Osaka, Japan) for 3 days as described in a previous report (Sato et al., 2011). The medium was then changed to IEC maintenance medium without Y-27632, and cultured for 20-22 days with medium changed every 2 or 3 days.

Caco- 2 cells were cultured in DMEM (Thermo Fisher Scientific) supplemented with $10 \%$ fetal bovine serum (Equitech-Bio, Kerrville, TX), $1 \%$ non-essential amino acid (NEAA), $100 \mathrm{IU} / \mathrm{ml}$ of penicillin-streptomycin, and $6 \mathrm{mM}$ HEPES on a 10-cm culture dish. Cells were harvested with trypsin (0.25\%)-EDTA (1 mM) and seeded on porous polyester membrane Transwell filters $(0.4-\mu \mathrm{m}$ pore size and $0.33-\mathrm{cm}^{2}$ filter area) at a density of $1.3 \times 10^{5} \mathrm{cells} / \mathrm{cm}^{2}$. The culture medium was replaced every 2 or 3 days.

The resistance $(\Omega)$ of hiPSC-IEC and Caco-2 cell monolayers was measured on each Transwell insert by a Millicell ERS-2 system (EMD Millipore, Bedford, MA), and corrected for background resistance with an insert that did not contain cells. The transepithelial electrical resistance (TEER; $\Omega \times \mathrm{cm}^{2}$, an index of the formation of tight junctions) of hiPSC-IEC and Caco- 2 cell monolayers was determined as the product of the resistance $(\Omega)$ and the surface area of insert $\left(0.33 \mathrm{~cm}^{2}\right)$. All cultures were performed at $37^{\circ} \mathrm{C}$ in a humidified atmosphere of $5 \% \mathrm{CO}_{2}$ and $95 \%$ air.

Quantification of Gene Expression of Transporters and Metabolic Enzymes Using a Quantitative Polymerase Chain Reaction. Total RNAs of human iPS cells, hiPSC-IECs, and Caco-2 cells were isolated by using a PureLink RNA Mini Kit (Invitrogen/Thermo Fisher Scientific, Carlsbad, CA). The quantitative polymerase chain reaction (qPCR) analyses for nine genes [P-gp, BCRP, PEPT1, CYP3A4, CYP3A7, CES1, CES2, UDP-glucuronosyltransferase (UGT)1A1, and glyceraldehyde-3-phosphate dehydrogenase (GAPDH) (primer 1)] were performed by means of a 7500 Real Time PCR System (Applied Biosystems, Carlsbad, CA) using a TaqMan Fast Universal PCR Master Mix (Applied Biosystems). Three CYP3A isoforms, CYP3A4, CYP3A5, and CYP3A7, are known to express in human small intestine (Miyauchi et al., 2016). The present study measured the gene expression of CYP3A4 and CYP3A7 as predominant CYP3A isoforms in adult and fetal human small intestine, respectively (Shin et al., 2009; Betts et al., 2015; Miyauchi et al., 2016). The cDNA was synthesized with a High-Capacity cDNA Reverse Transcription Kit (Applied Biosystems). The reaction solution for cDNA synthesis consisted of $10 \mu \mathrm{l}$ of RNA, $2 \mu \mathrm{l}$ of $10 \times \mathrm{RT}$ buffer, $2 \mu \mathrm{l}$ of $10 \times \mathrm{RT}$ random primers, $0.8 \mu \mathrm{l}$ of $25 \times$ dNTP Mix (100 mM), $1 \mu \mathrm{l}$ of MultiScribe Reverse Transcriptase (50 IU/ $\mu \mathrm{l}$; Thermo Fisher Scientific), and $4.2 \mu \mathrm{l}$ of distilled water. The reverse transcription reactions were conducted with an Applied Biosystems 7500 Real Time PCR System under the following conditions: $25^{\circ} \mathrm{C}$ for 10 minutes, $37^{\circ} \mathrm{C}$ for 120 minutes, and $85^{\circ} \mathrm{C}$ for 5 minutes. The resulting cDNA samples were subjected to qPCR analyses. The reaction solution consisted of $1 \mu \mathrm{l}$ of cDNA, $1 \mu \mathrm{l}$ of TaqMan primer-probe set (Applied Biosystems), $10 \mu 1$ of $2 \times$ TaqMan Fast Universal PCR Master Mix, and $8 \mu \mathrm{l}$ of distilled water. The qPCR reactions were performed under the following conditions: $95^{\circ} \mathrm{C}$ for 10 seconds, followed by 
50 cycles of $95^{\circ} \mathrm{C}$ for 3 seconds, $60^{\circ} \mathrm{C}$ for 30 seconds. Information on the TaqMan primer-probe set is given in Supplemental Table S2. The expression level of each target gene was normalized relative to that of GAPDH (primer 1). The relative expression of the target gene to GAPDH was calculated using the comparative $\Delta \mathrm{Ct}$ method, where $\Delta \mathrm{Ct}$ is obtained by subtracting $\mathrm{Ct}$ of GAPDH from the target gene. The relative expression levels of target gene to GAPDH were expressed as $2^{-\Delta \mathrm{Ct}}$.

Transcellular Transport Study across hiPSC-IEC and Caco-2 Cell Monolayers. MES transport buffer and HEPES transport buffer were used for transcellular transport experiments. Transport buffers contained $1.26 \mathrm{mM} \mathrm{CaCl}_{2}$, $0.493 \mathrm{mM} \mathrm{MgCl}, 0.407 \mathrm{mM} \mathrm{MgSO}_{4}, 5.33 \mathrm{mM} \mathrm{KCl}, 0.441 \mathrm{mM} \mathrm{KH}_{2} \mathrm{PO}_{4}$, $12.8 \mathrm{mM} \mathrm{NaHCO}_{3}, 138 \mathrm{mM} \mathrm{NaCl}, 0.338 \mathrm{mM} \mathrm{Na}_{2} \mathrm{HPO}_{4}, 30.6 \mathrm{mM}$ D-glucose, $5 \%$ fetal bovine serum, and either $25 \mathrm{mM}$ MES (MES transport buffer) or $25 \mathrm{mM}$ HEPES (HEPES transport buffer). The pH values of the MES transport buffer and HEPES transport buffer were adjusted to 6.0 and 7.4 with $\mathrm{NaOH}$ or $\mathrm{HCl}$, respectively. The conditions of transcellular transport studies across hiPSC-IEC or Caco-2 cell monolayers are described in the following sections: Transport Activities of P-gp and BCRP in hiPSC-IEC Monolayers, Transport Activities of PEPT1 in hiPSC-IEC Monolayers, Metabolic Activities of CYP3A4, CES2, and CES1 in hiPSC-IEC and Caco-2 Cell Monolayers, Hydrolytic Activities of Six Ester Prodrugs in hiPSC-IEC Monolayers, Permeation Experiment of 14 Drugs Across hiPSC-IEC Monolayers for Comparison of $P_{a p p}$ Values with Human Fa.

Transport Activities of P-gp and BCRP in hiPSC-IEC Monolayers. The functions of P-gp and BCRP were examined by means of bidirectional (apical-tobasolateral and basolateral-to-apical) transcellular transport studies in hiPSC-IEC monolayers. The functional assessments of P-gp and BCRP were not performed in Caco- 2 cell monolayers in the present study. $\left[{ }^{3} \mathrm{H}\right] \operatorname{Digoxin}(1 \mu \mathrm{M}, 1.0 \mu \mathrm{Ci} / \mathrm{ml})$ and cyclosporin A $(10 \mu \mathrm{M})$ were used as a probe substrate and an inhibitor for P-gp, respectively, and sulfasalazine $(2 \mu \mathrm{M})$ and $\mathrm{KO} 143(0.1 \mu \mathrm{M})$ were used as a probe substrate and an inhibitor for BCRP, respectively. Prior to the transcellular transport experiments, both sides of the cell monolayers were preincubated with HEPES transport buffer in the presence or absence of each transporter inhibitor for 30 minutes. After preincubation, the transport experiment was initiated by replacement with HEPES transport buffer containing each transporter substrate in the presence or absence of each transporter inhibitor on the donor side, and replacement without each transporter substrate in the presence or absence of each transporter inhibitor on the receiver side. The cell monolayers were incubated at $37^{\circ} \mathrm{C}$ under gentle shaking with a horizontal rotary shaker (MMS-1; EYELA, Tokyo, Japan). Aliquots of solution were collected from the receiver compartment 1,2 , and 3 hours after addition of each probe substrate, and the same volume of fresh transport buffer was immediately added except for the sampling at 3 hours.

The apparent permeability coefficient $\left(P_{a p p}\right)(\mathrm{cm} / \mathrm{s})$ of each compound was calculated according to the following equation:

$$
P_{a p p}=\frac{d Q}{d t} \times \frac{1}{A \times C_{0}}
$$

where $d Q / d t(\mathrm{pmol} / \mathrm{s})$ is the flux rate of the test compound across the monolayer and is determined by the slope of the plots of the cumulative permeated amount on the receiver side versus time using linear regression analysis of the transcellular transport. $A$ is the surface area of the monolayer $\left(0.33 \mathrm{~cm}^{2}\right)$, and $C_{0}(\mathrm{pmol} / \mu \mathrm{l})$ is the initial concentration of test compounds on the donor side.

The contributions of efflux activities of P-gp and BCRP were defined by the efflux ratio as follows:

$$
\text { Efflux ratio }=\frac{P_{\text {app }, \text { bto a }}}{P_{\text {app }, \text { ato }}}
$$

where $P_{a p p, b \text { to a }}(\mathrm{cm} / \mathrm{s})$ and $P_{\text {app, a to } b}(\mathrm{~cm} / \mathrm{s})$ represent the apparent permeability coefficients in the basolateral-to-apical direction and apical-to-basolateral direction, respectively.

Transport Activities of PEPT1 in hiPSC-IEC Monolayers. The function of PEPT1 was examined by means of unidirectional (apical-to-basolateral) transcellular transport studies. The basolateral-to-apical transcellular transport studies were not performed in hiPSC-IEC monolayers. In this study, the function of PEPT1 was also not examined in Caco-2 cell monolayers. Prior to transcellular transport experiments, cell monolayers were preincubated with MES transport buffer on the apical side and with HEPES transport buffer on the basolateral side in the presence or absence of a PEPT1 inhibitor (10 mM unlabeled glycylsarcosine) for 30 minutes, respectively. The transport experiment was initiated by replacement with MES transport buffer containing $\left[{ }^{14} \mathrm{C}\right]$ glycylsarcosine $(10 \mu \mathrm{M}$, $1.0 \mu \mathrm{Ci} / \mathrm{ml}$ ), a PEPT1 substrate, in the presence or absence of $10 \mathrm{mM}$ unlabeled glycylsarcosine on the apical side, and with HEPES transport buffer without $\left[{ }^{14} \mathrm{C}\right]-$ glycylsarcosine in the presence or absence of $10 \mathrm{mM}$ unlabeled glycylsarcosine on the basolateral side. The cell monolayers were incubated at $37^{\circ} \mathrm{C}$ under gentle shaking with a horizontal rotary shaker (MMS-1). The aliquots of solution were collected from the basolateral side 1,2 , and 3 hours after adding $\left[{ }^{14} \mathrm{C}\right]-$ glycylsarcosine, and then the same volume of fresh transport buffer was immediately added except for the sampling at 3 hours. The values of $P_{a p p}$ $(\mathrm{cm} / \mathrm{s})$ of $\left[{ }^{14} \mathrm{C}\right]$ glycylsarcosine across hiPSC-IEC monolayers were determined according to eq. 1 .

Metabolic Activities of CYP3A4, CES2, and CES1 in hiPSC-IEC and Caco-2 Cell Monolayers. The functions of CYP3A4, CES2, and CES1 were examined by means of unidirectional (apical-to-basolateral) transcellular transport studies performed under the same conditions as described in Transport Activities of PEPT1 in hiPSC-IEC Monolayers except for sampling times. Cells were preincubated with each metabolic enzyme inhibitor [0.5 or $10 \mu \mathrm{M}$ ketoconazole (a CYP3A4 inhibitor), $100 \mu \mathrm{M}$ telmisartan (a CES2 inhibitor), or $500 \mu \mathrm{M}$ bisp-nitrophenyl phosphate (BNPP) (a CES inhibitor)] for 30 minutes. The preincubation buffer was replaced with MES transport buffer containing each metabolic enzyme substrate [ $2 \mu \mathrm{M}$ midazolam (a CYP3A4 substrate), $100 \mu \mathrm{M}$ irinotecan (a CES2 substrate), or $100 \mu \mathrm{M}$ temocapril (a CES1 substrate)] in the presence or absence of each metabolic enzyme inhibitor as described above on the donor side, and replaced with HEPES transport buffer without each metabolic enzyme substrate in the presence or absence of each metabolic enzyme inhibitor on the receiver side. The aliquots of solution were collected from the apical and basolateral compartments 2 hours after adding each probe substrate, cell monolayers were washed with HEPES transport buffer, then test substrates in the cells were extracted with acetonitrile.

The contribution of drug metabolism to drug permeation across the cell monolayer was defined by the extraction ratio proposed by Fisher et al. (1999). The extraction ratio (\%) was calculated according to the following equation:

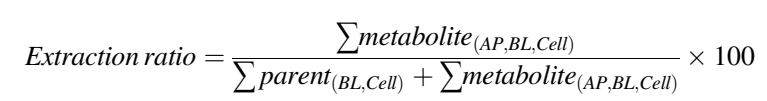

where $\sum \operatorname{parent}_{(B L, C e l l)}(\mathrm{pmol})$ is the summed amount of parent compound (midazolam, irinotecan, or temocapril) in basolateral (BL) and intracellular (Cell) compartments at the end of the study, and $\sum$ metabolite $\left._{(A P, B L}, C e l l\right)(\mathrm{pmol})$ is the summed amount of the metabolites (1-OH midazolam, SN-38, or temocaprilat) in apical $(A P)$, basolateral, and intracellular compartments at the end of the study.

Hydrolytic Activities of Six Ester Prodrugs in hiPSC-IEC Monolayers. The function was examined by means of unidirectional (apical-to-basolateral) transcellular transport studies across hiPSC-IEC monolayers under the same conditions as described in Metabolic Activities of CYP3A4, CES2, and CES1 in hiPSC-IEC and Caco-2 Cell Monolayers.

The intrinsic clearance $\left(\mathrm{CL}_{\text {int }}\right)(\mu 1 / \mathrm{min})$ of each prodrug was calculated according to the following equation:

$$
C L_{\text {int }}=\frac{\sum A F_{(A P, B L, \text { Cell })} / t}{C_{0, P D(A P)}}
$$

where $\sum A F_{(A P, B L, C e l l)}(\mathrm{pmol})$ is the summed amount of the active form in apical $(A P)$, basolateral $(B L)$, and intracellular $(C e l l)$ compartments at the end of the study, $t$ is the reaction time (120 minutes), and $C_{O, P D(A P)}$ is the initial concentration of test prodrugs on the apical side.

Permeation Experiment of 14 Drugs across hiPSC-IEC Monolayers for Comparison of $\boldsymbol{P}_{a p p}$ Values with Human $\boldsymbol{F} \boldsymbol{a}$. The apical to basolateral permeabilities of 14 drugs (ganciclovir, doxorubicin, sulfasalazine, $\left[{ }^{14} \mathrm{C}\right]$ mannitol, sulpiride, famotidine, ranitidine, atenolol, furosemide, hydrochlorothiazide, $\left[{ }^{3} \mathrm{H}\right]$ digoxin, acetaminophen, propranolol, and antipyrine) were measured under the same conditions as described in Transport Activities of PEPT1 in hiPSC-IEC Monolayers except for sampling times. Test concentrations of ganciclovir, doxorubicin, $\left[{ }^{14} \mathrm{C}\right]$ mannitol, sulfasalazine, and $\left[{ }^{3} \mathrm{H}\right]$ digoxin were set at 100,2,10 $(20 \mu \mathrm{Ci} / \mathrm{ml}), 2$, and $1 \mu \mathrm{M}(1 \mu \mathrm{Ci} / \mathrm{ml})$, respectively, and the test concentration of the other nine drugs (famotidine, 
sulpiride, atenolol, furosemide, ranitidine, hydrochlorothiazide, acetaminophen, propranolol, and antipyrine) was set at $10 \mu \mathrm{M}$. For propranolol and antipyrine transport studies, sampling times were set at 30,60, and 90 minutes, and for the other 12 compound transport studies, sampling times were set at 1 , 2 , and 3 hours.

In transcellular transport assessment using Caco-2 cells, the $\mathrm{K}_{\mathrm{m}}$ values of doxorubicin, digoxin for P-gp, and sulfasalazine for BCRP were reported to be $>100,177$, and $369 \mu \mathrm{M}$, respectively (Liang et al., 2000; Troutman and Thakker, 2003; Kim et al., 2013). The concentrations of these drugs in the present study were well below their reported $\mathrm{K}_{\mathrm{m}}$ values, assuming that these transporters were not saturated.

When the drug migration in the gastrointestinal tract is assumed to follow a well stirred model according to the previous report (Amidon et al., 1988), the following equations are obtained:

$$
\begin{gathered}
C_{\text {out }} / C_{\text {in }}=e^{\left\{-(S / V) \times P_{\text {app }} \times t_{\text {res }}\right\}} \\
C_{\text {out }} / C_{\text {in }}=1-F a \\
F a=1-e^{\left\{-(S / V) \times P_{\text {app }} \times t_{\text {res }}\right\}}=e^{-S F \times \text { Papp }} \\
\left(\mathrm{SF}=(\mathrm{S} / \mathrm{V}) \times \mathrm{t}_{\text {res }}\right)
\end{gathered}
$$

where $C_{\text {in }}$ and $C_{\text {out }}$ represent the drug concentration of the inlet and outlet of the gastrointestinal tract, respectively. $S$ and $V$ represent the surface area and volume of the gastrointestinal tract per unit length of the small intestine, respectively. The term $t_{r e s}$ represents the average residence time of drugs in small intestine. $P_{a p p}$ represents the permeability coefficient of intestinal epithelial cells and can be estimated by transcellular transport study across hiPSC-IEC monolayers. Since $S$, $V$, and $t_{r e s}$ are treated as fixed values, $S F$ (the empirical scaling factor) can be obtained by the fitting study between $P_{a p p}$ in hiPSC-IECs and human $F a$ of 14 drugs using a nonlinear least-squares method by XLfit software (ID Business Solution, Guildford, UK).

Pharmacokinetic Studies of Six Ester Prodrugs in Rats. For oral administration studies of six ester prodrugs, each was suspended in an aqueous solution of $0.5 \%(\mathrm{w} / \mathrm{v})$ methylcellulose 400 centipoise $(\mathrm{cP})$ at a concentration of $1 \mathrm{mg} / 5 \mathrm{ml}$ per kilogram as its active form and orally administrated to rats $(n=2$ or 3). Rats had been anesthetized with isoflurane and catheterized into the jugular vein for subsequent blood sampling 3 days before the experiment. Blood samples were collected from the jugular vein with a heparinized syringe $0.25,0.5,1,2,4$, 6,8 , and 24 hours after administration.

For intravenous administration studies of the active form, this form was dissolved in dimethyl acetamide and propylene glycol solution $(1: 1, \mathrm{v} / \mathrm{v})$ at a concentration of $1 \mathrm{mg} / 1 \mathrm{ml}$ per kilogram, and administered via the caudal vein to rats $(n=3)$. Blood samples were collected from the jugular vein with a heparinized syringe $0.033,0.083,0.25,0.5,1,2,4,6,8$, and 24 hours after administration.

The collected blood samples were centrifuged at $1310 \mathrm{~g}$ for 10 minutes at $4^{\circ} \mathrm{C}$, and the resulting supernatants were collected as plasma samples. The pharmacokinetic parameters for the plasma concentration of the active form were calculated via noncompartmental analysis by using WinNonlin 5.0 software (Pharsight, Mountain View, CA) with uniform weighting. The $C_{\max }(\mathrm{ng} / \mathrm{ml})$ was the maximum concentration among the sampling times $(0.25,0.5,1,2,4,6,8$, and 24 hours after oral administration). The AUC $(\mathrm{ng} \times \mathrm{h} / \mathrm{ml})$ was calculated by the linear trapezoidal method. $B A(\%)$ was calculated using the following equation:

$$
B A=\frac{A U C_{\text {p.o. }} / \text { Dose }_{\text {p.o. }}}{A U C_{\text {i.v. }} / \text { Dose }_{i . v .}} \times 100
$$

where $A U C_{\text {p.o. }}$ and Dose $_{\text {p.o. }}$ represent AUC $(\mathrm{ng} \times \mathrm{h} / \mathrm{ml})$ of the active form and the dose of prodrugs ( $1 \mathrm{mg} / \mathrm{kg}$ as the active form) for oral administration of prodrugs, respectively. $A U C_{i . v .}$ and $D_{\text {ose }} e_{\text {i. } .}$ represent AUC $(\mathrm{ng} \times \mathrm{h} / \mathrm{ml})$ of the active form and dose $(1 \mathrm{mg} / \mathrm{kg})$ for intravenous administration of the active form, respectively.

Measuring Radioactivity Using a Liquid Scintillation Counter. Samples of radiolabeled compounds, $\left[{ }^{14} \mathrm{C}\right]$ mannitol, $\left[{ }^{3} \mathrm{H}\right]$ digoxin, and $\left[{ }^{14} \mathrm{C}\right]$ glycylsarcosine, were mixed with Pico-Fluor Plus (PerkinElmer/Thermo Fisher Scientific). The radioactivity levels were measured using a liquid scintillation counter (Tri-Carb 3100TR; PerkinElmer).

Quantification of Test Compounds Using Liquid ChromatographyTandem Mass Spectrometry. The concentrations of test compounds except for radiolabeled compounds were quantified using liquid chromatography-tandem mass spectrometry (LC-MS/MS). The samples were stored at $-20^{\circ} \mathrm{C}$ until determination of the compounds. For the transcellular transport studies in hiPSCIECs and Caco-2 cells, a 6-fold volume of acetonitrile was added to the samples, whereas for the pharmacokinetic studies in rat, a 12.5-fold volume of acetonitrile was added to samples. The samples were centrifuged at $1880 \mathrm{~g}$ for 5 minutes at $4^{\circ} \mathrm{C}$, and then the resulting supernatants were injected into the LC-MS/MS system. The measurement conditions for LC-MS/MS were developed in Shionogi $\&$ Co., Ltd. The detailed LC-MS/MS conditions are shown in Supplemental Table S4. Chromatogram ion counts were determined by using Analyst software version 1.6 (SCIEX, Framingham, MA) or MassLynx software version 4.1 (Waters Corporation, Milford, MA).

For the quantifications of test compounds using LC-MS/MS, a calibration curve was prepared using a dilution series of each compound. The concentrations of calibration standards are back-calculated, and the difference between the backcalculated concentration of the calibration standard and its nominal concentration was determined. The present study accepted the range of calibration standards if the difference between the back-calculated concentration of the calibration standard and its nominal concentration was within $\pm 15 \%$, and the lowest concentration in the calibration standard was defined as a limit of quantification.

Statistical Analysis. The statistical significance of differences between two groups was determined by Student's $t$ test. A value of $P<0.05$ was considered statistically significant.

\section{Results}

Generation of hiPSC-IECs. Differentiation from hiPSCs to human intestinal epithelial cells was verified by determining the differentiation markers for hiPSCs, definitive endoderms (DEs), hindguts (HGs), and intestinal epithelial cells, according to the differentiation methods described in Supplemental Data. In the differentiated DEs, the gene expression levels of DE markers, SRY (sex-determining region Y)-box (SOX)17, forkhead box protein A2 (FOXA2), and GATA binding protein 4 (GATA4), were markedly higher than in hiPSCs (Supplemental Fig. S2A). Immunofluorescence analysis also showed that the protein expression of SOX17 was detected in DEs but not in hiPSCs (Supplemental Fig. S2B). The differentiated HGs dramatically increased the gene expression level of HG marker caudal type homeobox 2 (CDX2) compared with that in hiPSCs and DEs (Supplemental Fig. $\mathrm{S} 2 \mathrm{~A}$ ). The protein expression of CDX2 was also detected in HGs but not in hiPSCs and DEs by immunofluorescence analysis (Supplemental Fig. S2B). Furthermore, undifferentiated markers octamer-binding transcription factor 3/4 (OCT3/4) and SOX2 gradually decreased in the process of differentiation of DEs and HGs (Supplemental Fig. S2A). When hiPSCIECs isolated from intestinal organoids by means of the magnetically activated cell-sorting technique were cultured on Transwell insert for 21 days, the gene expressions of the enterocyte markers leucine-rich repeat containing $\mathrm{G}$ protein-coupled receptor 5 (LGR5) and intestinespecific homeobox (ISX), the intestinal epithelial markers villin-1 (VIL) and sucrase-isomaltase (SI), the paneth cell marker lysozyme (LYZ), the endocrine cell marker chromogranin A (CHGA), and the goblet cell markers mucin 2 (MUC2) and trefoil factor 3 (TFF3) increased compared with those in hiPSCs (Supplemental Fig. S3).

Gene Expression of Transporters and Metabolic Enzymes in hiPSC-IECs, iPSCs, Caco-2 Cells, Adult Small Intestine, and Fetal Small Intestine. The gene expression levels of transporters (P-gp, BCRP, and PEPT1) and metabolic enzymes (CYP3A4, CYP3A7, CES1, CES2, and UGT1A1) in hiPSC-IECs 21 days after cultivation on Transwell inserts (day 21) were compared with adult and fetal small intestine, Caco- 2 cells, hiPSCs, and hiPSC-IECs before cultivation on Transwell inserts (day 0) (Fig. 1).

Comparing the gene expression between day 0 and day 21 of hiPSCIECs showed higher expression levels at day 21 than at day 0 for P-gp, BCRP, PEPT1, CYP3A4, CES2, and UGT1A1 (5.13-, 16.7-, 2.08-, 5.06-, 1.70-, and 3.29-fold, higher, respectively), although there were no 


\section{$\square$ Adult intestine $\square$ Fetal intestine $\square$ Caco-2 $\square$ hiPSCs $\square$ Day0 $\square$ Day7 $\square$ Day14 $\square$ Day21}

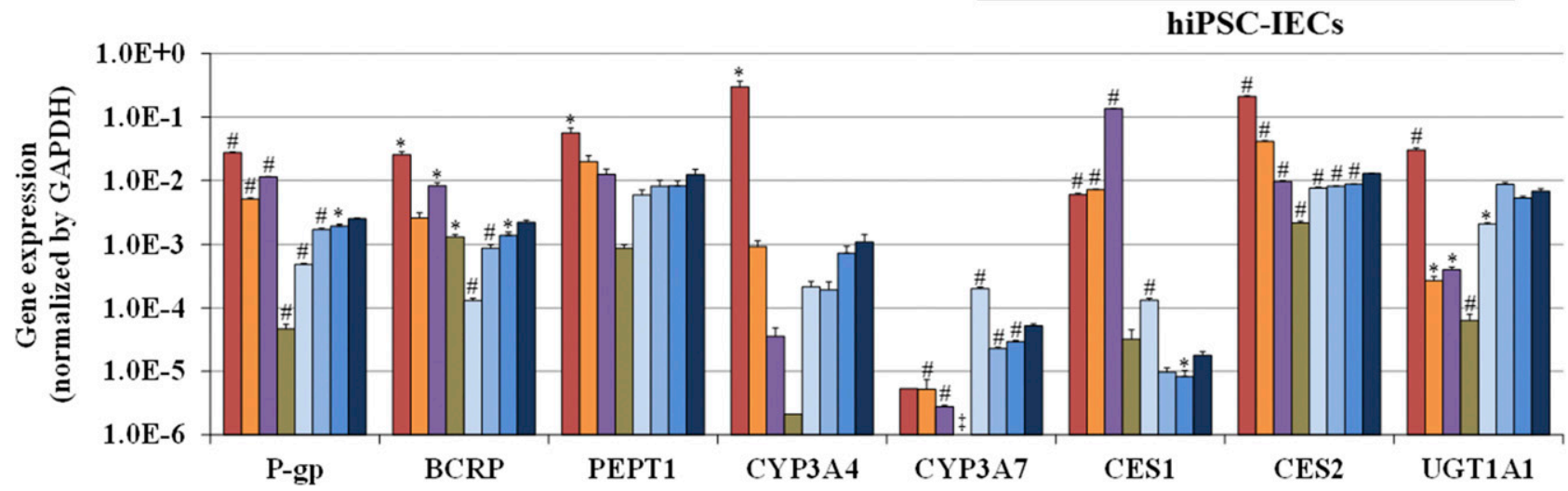

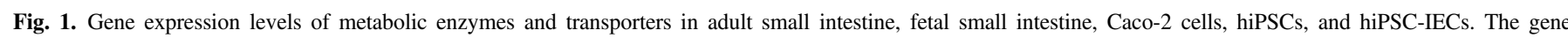

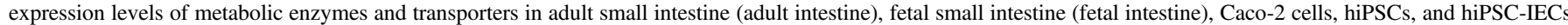

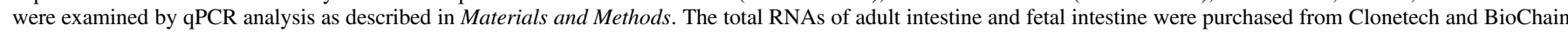

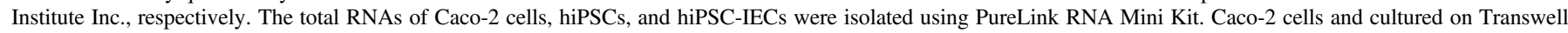

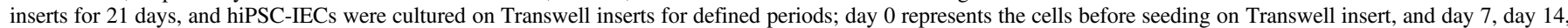

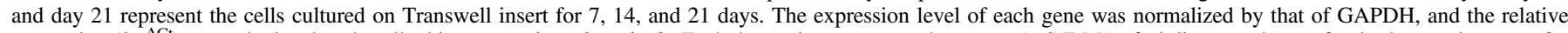

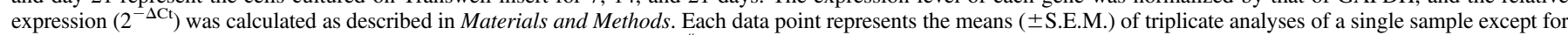

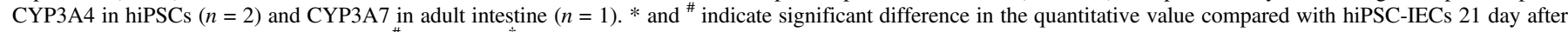
seeding on Transwell insert $\left({ }^{*} P<0.05 ;{ }^{\#} P<0.01\right)$. ${ }^{*}$ The gene was not detected.

significant differences for PEPT1 and CYP3A4 expression between day 0 and day 21. In contrast, molecules showing lower expression levels at 21 day than at 0 day were CYP3A7 and CES1 (3.87- and 7.38-fold, lower, respectively). For the comparison of expression between hiPSC-IECs of 21-day cultivation and adult small intestine, P-gp, BCRP, PEPT1, CYP3A4, CES1, CES2, and UGT1A1 in hiPSC-IECs were expressed at 11.1-, 11.6-, 4.59-, 274-, 336-, 16.4-, and 4.46-fold lower levels than those in adult small intestine, respectively. Comparing expression between hiPSC-IECs of 21-day cultivation and Caco-2 cells, P-gp, BCRP, PEPT1, and CES1 expressions were 4.55-, 3.76-, 1.02-, 7580-fold, respectively, lower in hiPSC-IECs than in Caco-2 cells, whereas CYP3A4, CYP3A7, CES2, and UGT1A1 expressions were 30.6-, 18.8-, 1.33-, 16.9-fold higher, respectively, in hiPSC-IECs than in Caco-2 cells.

Formation of Tight Junction in hiPSC-IEC and Caco-2 Cell Monolayers. The TEER value and the permeability of $\left[{ }^{14} \mathrm{C}\right]$ mannitol, a paracellular marker, was examined to evaluate tight junction formation in hiPSC-IEC monolayers. The TEER value in hiPSC-IEC monolayers on 24-well Transwell inserts was recorded every 1-3 days until 21 days after seeding on Transwell inserts. The TEER values in hiPSC-IEC monolayers increased in a time-dependent manner and reached $329 \pm 20\left(\Omega \times \mathrm{cm}^{2}\right) 21$ days after seeding on Transwell inserts (Fig. 2A). In contrast, the TEER values in Caco- 2 cell monolayers were $891 \pm 26\left(\Omega \times \mathrm{cm}^{2}\right) 21$ days after seeding on Transwell inserts, significantly higher than those in hiPEC monolayers. The $P_{a p p}$ values of $\left[{ }^{14} \mathrm{C}\right]$ mannitol in hiPSC-IEC and Caco- 2 cell monolayers 21 days after seeding on Transwell inserts were $0.222 \pm 0.020\left(\times 10^{-6} \mathrm{~cm} / \mathrm{s}\right)$ and $0.167 \pm 0.007\left(\times 10^{-6} \mathrm{~cm} / \mathrm{s}\right)$, respectively (Fig. 2B). There was no significant difference in the $P_{a p p}$ values of $\left[{ }^{14} \mathrm{C}\right]$ mannitol between hiPSC-IECs and Caco-2 cells. These results suggested that hiPSC-IECs formed tight junctions. Detail discussion for formation of tight junction in hiPSC-IECs is described in the Supplemental Data.
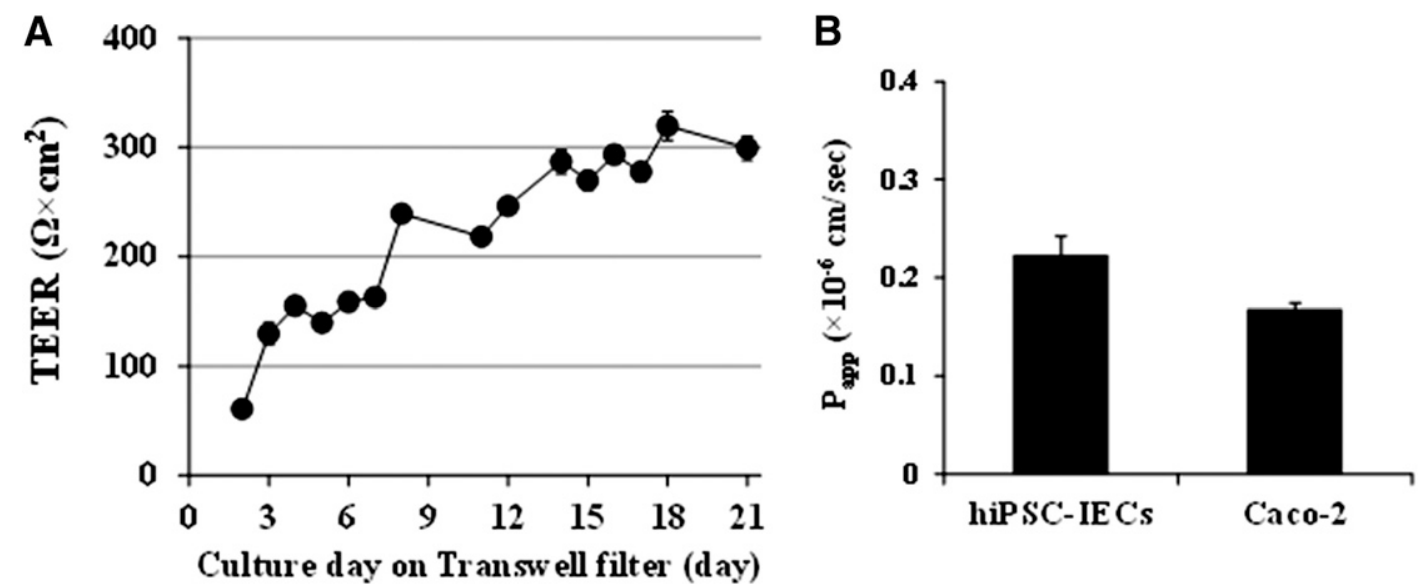

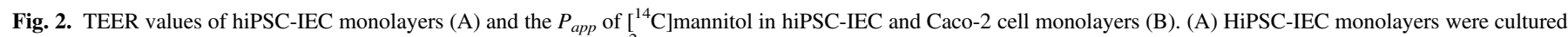

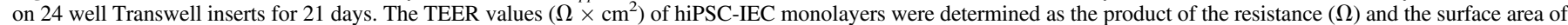

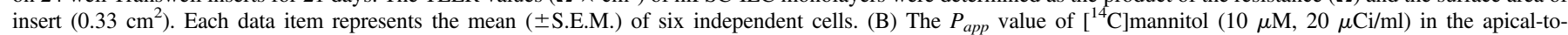

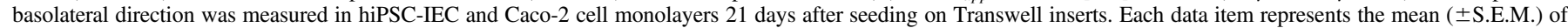
three independent experiments. 


\section{A} $\left[{ }^{3} \mathrm{H}\right]$ Digoxin

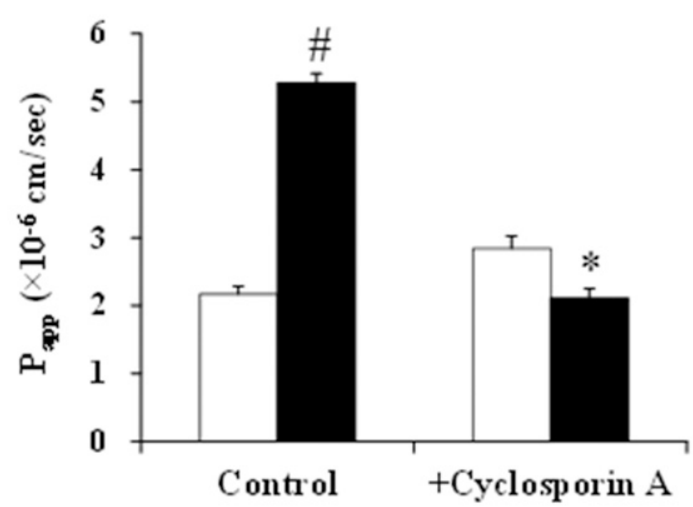

C

$\left[{ }^{14} \mathrm{C}\right]$ Glycylsarcosine

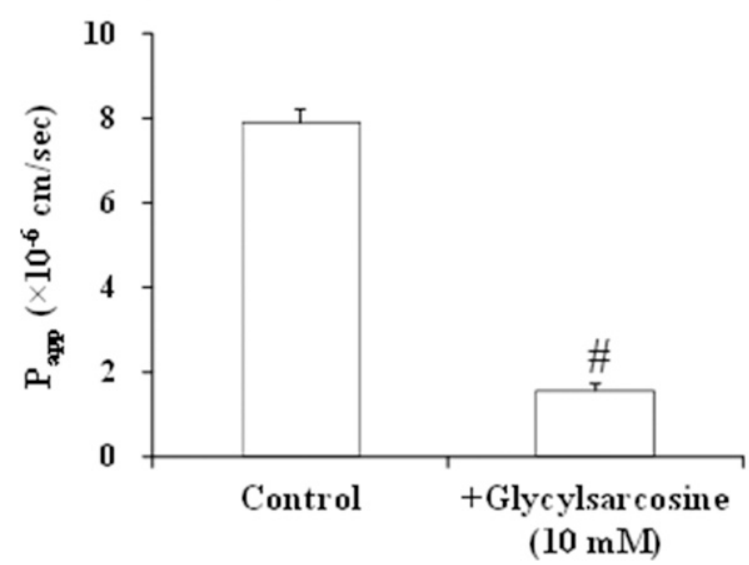

${ }^{B}$ Sulfasalazine

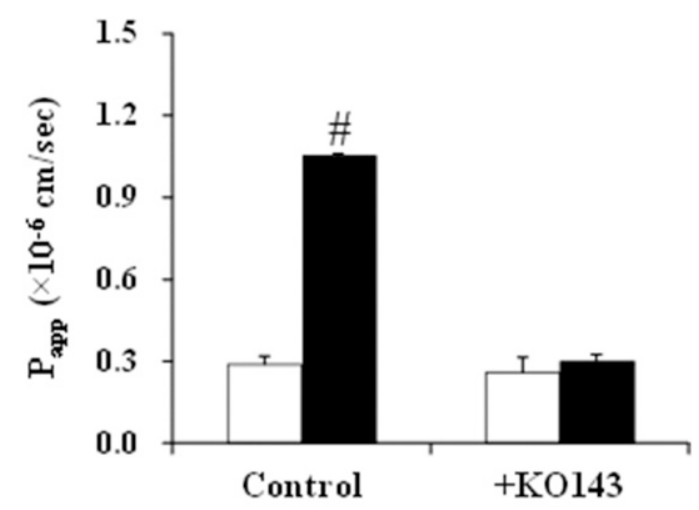

$\square$ Apical-to-basolateral direction Basolateral-to-apical direction

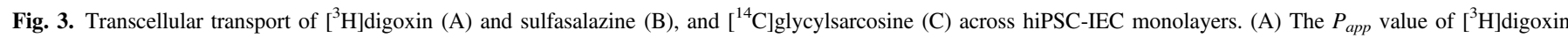

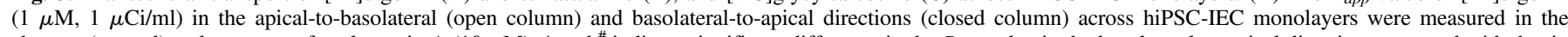

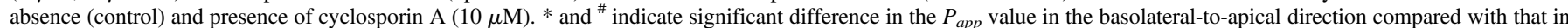

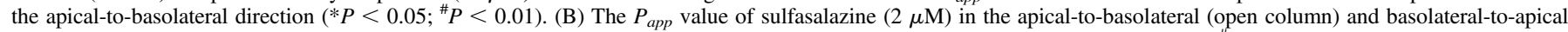

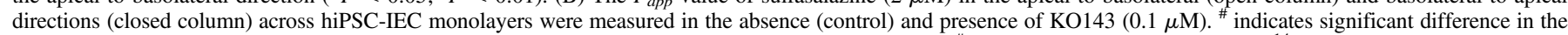

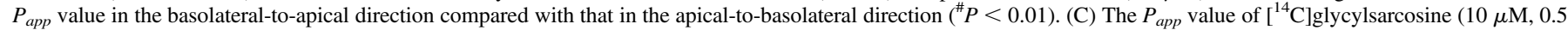

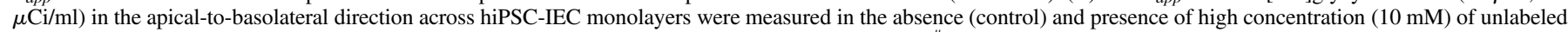

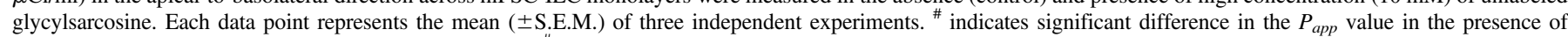
unlabeled glycylsarcosine compared with that of control $\left({ }^{\#} P<0.01\right)$.

Functional Expression of P-gp and BCRP in hiPSC-IEC Monolayers. The bidirectional (apical-to-basolateral and basolateralto-apical) transcellular transport studies across hiPSC-IEC monolayers were performed to investigate the function of P-gp and BCRP in hiPSC-IECs. The $P_{a p p}$ values of $\left[{ }^{3} \mathrm{H}\right]$ digoxin (a P-gp substrate) in the basolateral-to-apical direction were significantly higher than those in apical-to-basolateral direction (efflux ratio, $2.43 \pm 0.18$ ), and the efflux ratio decreased to $0.743 \pm 0.083$ by $10 \mu \mathrm{M}$ cyclosporin A (a P-gp inhibitor) (Fig. 3A). Also, the $P_{a p p}$ values of sulfasalazine (a BCRP substrate) in the basolateral-to-apical direction were significantly higher than that in the apical-to-basolateral direction (efflux ratio, $3.65 \pm 0.49$ ), and the efflux ratio decreased to $1.16 \pm 0.33$ by $0.1 \mu \mathrm{M}$ KO143 (a BCRP inhibitor) (Fig. 3B). The membrane localizations of P-gp and BCRP in hiPSC-IECs were not measured by immunofluorescence confocal microscopy. However, the functional analysis of the P-gp and BCRP indicate that P-gp and BCRP are expressed in the apical membrane of hiPSC-IECs. Detail discussion for membrane localizations of P-gp and BCRP in hiPSC-IECs is described in the Supplemental Data.
Functional Expression of PEPT1 in hiPSC-IEC Monolayers. The apical-to-basolateral transport activity across hiPSC-IEC monolayers was measured to investigate the function of PEPT1 in hiPSC-IECs. The $P_{a p p}$ value of $10 \mu \mathrm{M}\left[{ }^{14} \mathrm{C}\right]$ glycylsarcosine (a PEPT1 substrate) was 7.90 $\pm 0.31\left(\times 10^{-6} \mathrm{~cm} / \mathrm{s}\right)$ and decreased to $1.56 \pm 0.17\left(\times 10^{-6} \mathrm{~cm} / \mathrm{s}\right)$ in the presence of a high concentration $(10 \mathrm{mM})$ of unlabeled glycylsarcosine (Fig. 3C). The result of functional analysis in the transcellular transport study indicates that PEPT1 is expressed in the apical membrane of hiPSC-IECs. See detailed discussion of membrane localizations of PEPT1 in hiPSC-IECs in the Supplemental Data.

Functional Expression of CYP3A4, CES2, and CES1 in hiPSCIEC Monolayers. The metabolic activities of CYP3A4, CES2, and CES1 in iPSC-IECs and Caco-2 cells were determined by the extraction ratio calculated by using eq. 3 . The extraction ratio of metabolism of midazolam (a substrate of CYP3A4) to 1-OH midazolam in hiPSC-IECs was $0.534 \pm 0.009(\%)$, and decreased to $0.322 \pm 0.009(\%)$ and 0.0821 $\pm 0.0064(\%)$ in the presence of 0.5 and $10 \mu \mathrm{M}$ ketoconazole (an inhibitor of CYP3A4), respectively (Fig. 4A). The extraction ratio in Caco-2 cells was $0.0623 \pm 0.0038(\%)$ and also decreased to 0.0404 
A

Midazolam

$\square$ Control $\square+$ Ketoconazole $(0.5 \mu M) \square+$ Ketoconazole $(10 \mu M)$

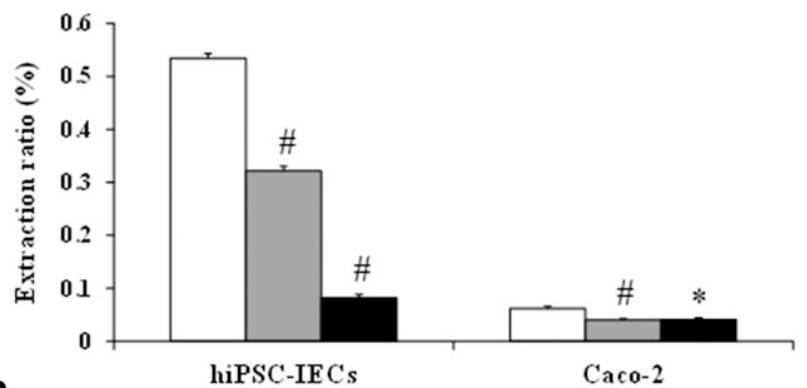

B

Irinotecan

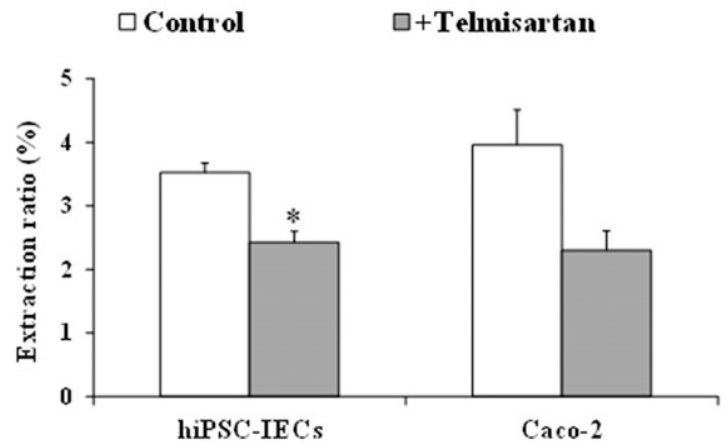

C

\section{Temocapril}

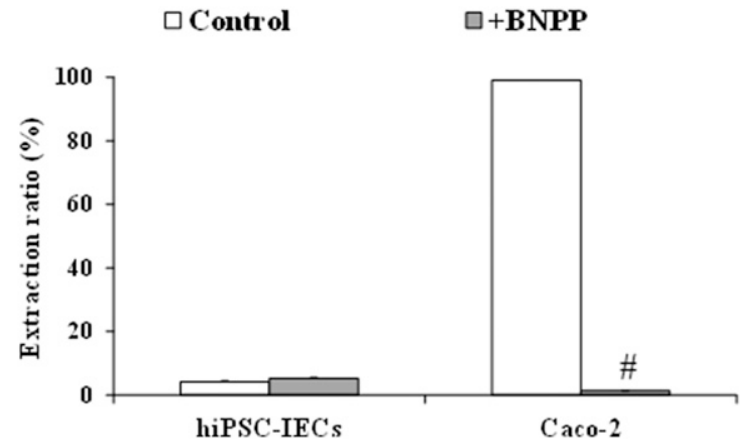

Fig. 4. Metabolism of midazolam (A), irinotecan (B), and temocapril (C) in hiPSCIEC and Caco- 2 cell monolayers. The extraction ratio, a parameter of the contribution of metabolism to permeation across cell monolayers, was determined by means of apical-to-basolateral transcellular transport study in hiPSC-IECs and Caco-2 cells according to the description in Materials and Methods. (A) White, gray, and black columns represent extraction ratio of metabolism of midazolam $(2 \mu \mathrm{M})$ to $1-\mathrm{OH}$ midazolam in the absence (control) and presence of ketoconazole $(0.5$ and $10 \mu \mathrm{M})$ in hiPSC-IECs and Caco-2 cells, respectively. (B) White and gray columns represent extraction ratio of metabolism of irinotecan $(100 \mu \mathrm{M})$ to SN-38 in the absence (control) and presence of telmisartan $(100 \mu \mathrm{M})$ in hiPSC-IECs and Caco2 cells, respectively. (C) White and gray columns represent extraction ratio of metabolism of temocapril $(100 \mu \mathrm{M})$ to temocaprilat in the absence (control) and presence of BNPP $(500 \mu \mathrm{M})$ in hiPSC-IECs and Caco-2 cells, respectively. Each datum represents the mean \pm S.E.M. $(n=3)$. * and ${ }^{\#}$ indicate significant difference in the value of extraction ratio in the presence of inhibitor compared with that of control $\left({ }^{*} P<0.05 ;{ }^{\#} P<0.01\right)$

$60.0023(\%)$ and $0.0414 \pm 0.0032(\%)$ in the presence of 0.5 and $10 \mu \mathrm{M}$ ketoconazole, respectively (Fig. 4A).

The extraction ratio of metabolism of irinotecan (a CES2 substrate) to SN-38 in hiPSC-IECs was $3.52 \pm 0.15(\%)$ and decreased to $2.42 \pm$ $0.17(\%)$ in the presence of $100 \mu \mathrm{M}$ telmisartan (a CES2 inhibitor) (Fig. 4B). The extraction ratio in Caco-2 cells was $3.96 \pm 0.55(\%)$ and also decreased to $2.30 \pm 0.30(\%)$ in the presence of $100 \mu \mathrm{M}$ telmisartan
(Fig. 4B). SN-38 is glucuronidated to SN-38 glucuronide by UGT1A1 (Hanioka et al., 2001). However, the positive chromatogram peak of SN-38 glucuronide by LC-MS/MS analysis was not detected in all samples of metabolic assessment of irinotecan in hiPSC-IECs and Caco2 cells (data were not shown).

The extraction ratio value of metabolism of temocapril (a CES1 substrate) to temocaprilat in the absence and presence of $500 \mu \mathrm{M}$ BNPP (a CES inhibitor) in hiPSC-IECs were $4.17 \pm 0.22(\%)$ and $5.18 \pm 0.30$ (\%), respectively (Fig. 4C). In contrast, the extraction ratio in Caco-2 cells was $99.0 \pm 0.1(\%)$ and decreased to $1.29 \pm 0.07(\%)$ in the presence of $500 \mu \mathrm{M}$ BNPP (Fig. 4C).

Comparison of Hydrolysis Activity of Six Prodrugs Between hiPSC-IEC Monolayers and Pharmacokinetic Parameters in Rats. The hydrolysis activities of six ester prodrugs (prodrugs A, B, C, D, E, and $\mathrm{F}$ ) to a common active form in hiPSC-IEC monolayers were assessed by $C L_{\text {int }}$ determined using eq. 4 . The values of $C_{\text {max }}$, AUC, and $\mathrm{BA}$ of the six prodrugs in SD rat were calculated from the plasma concentrations of the active form after oral administrations of the six prodrugs. As shown in Fig. 5 and Supplemental Table S5, the $C L_{i n t}$ values of the six prodrugs in hiPSC-IEC monolayers were correlated with $C_{\text {max }}$, AUC, and $B A$ in SD rat (correlation coefficients were 0.840 , 0815, and 0.815, respectively).

Comparison of the $\boldsymbol{P}_{\text {app }}$ Values of 14 Drugs across hiPSC-IEC Monolayers with Their $\mathbf{F a}$ Values in Humans. To examine whether $F a$ values in humans can be predicted from the values of $P_{a p p}$ across iPSC-IEC monolayers, the $P_{a p p}$ values of 14 compounds (ganciclovir, doxorubicin, $\left[{ }^{14} \mathrm{C}\right]$ mannitol, famotidine, sulpiride, atenolol, sulfasalazine, furosemide, ranitidine, hydrochlorothiazide, $\left[{ }^{3} \mathrm{H}\right]$ digoxin, acetaminophen, propranolol, and antipyrine) across iPSC-IECs were compared with their human $\mathrm{Fa}$ values taken from previous reports (Zhao et al., 2001; Sugano et al., 2002; Varma et al., 2010). If multiple $F a$ values were reported in these publications, the median value was calculated and used (Supplemental Table S6). As shown in Fig. 6, the $P_{a p p}$ values of 14 compounds in iPSC-IECs were correlated well with human $F a$ values (Fig. 6; Supplemental Table S6).

The value of $S F$ in eq. 7 was calculated as 2.96 from the correlation plot between the values of $P_{a p p}$ in hiPSC-IECs and human $F a$ of 14 drugs. Hence, the following equation for prediction of human $\mathrm{Fa}$ values from the $P_{a p p}$ values in hiPSC-IECs can be obtained:

$$
F a=e^{-2.96 \times P_{a p p}}
$$

As a result of the regression statistics between the predicted values of human $\mathrm{Fa}$ on the basis of the above equation and the observed ones of 14 drugs, the determination coefficient was calculated to be 0.691 . For 12 compounds, except for $\left[{ }^{14} \mathrm{C}\right]$ mannitol and ranitidine, the predicted human $F a$ values were within three fold-differences compared to observed ones (Supplemental Table S6).

\section{Discussion}

Many researchers have succeeded in generating hiPSC-IECs to show functions of intestinal transporters and metabolic enzymes (Spence et al., 2011; Kauffman et al., 2013; Ogaki et al., 2013; Forbester et al., 2015; Iwao et al., 2015; Ozawa et al., 2015; Uchida et al., 2017). However, whether these functions in oral drug absorption can be predicted using hiPSC-IECs remained to be clarified. This study is the first to demonstrate that the hydrolysis of six ester prodrugs into the active form in hiPSC-IECs was correlated with the plasma exposures of the active form after oral administration of these prodrugs in rats. Furthermore, the $P_{a p p}$ values of 14 drugs, containing substrates of $\mathrm{P}$-gp and BCRP, were correlated with their human $F a$ values. 

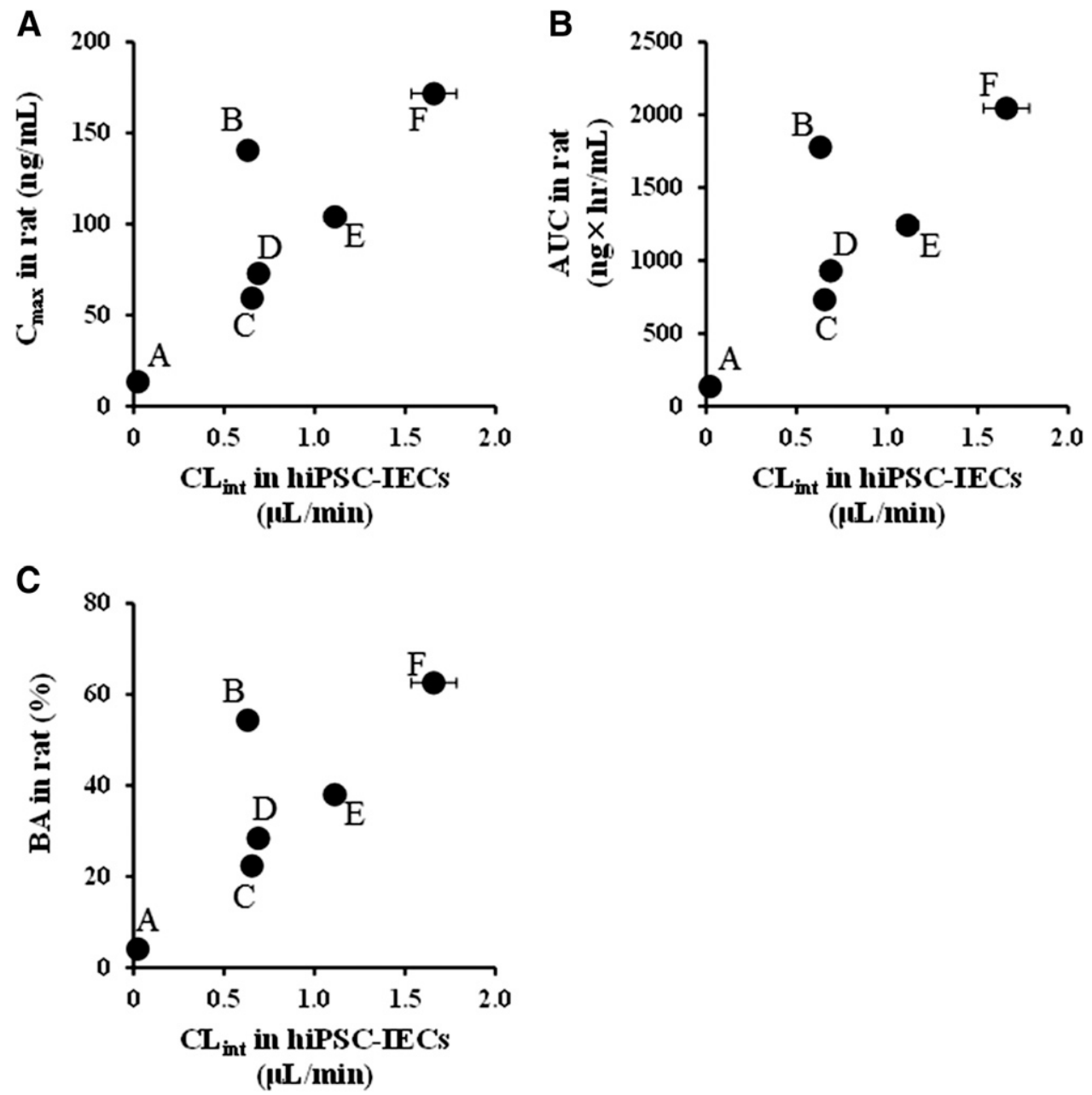

5. Comparison of hydrolysis activity of six ester prodrugs in hiPSC-IEC monolayers and pharmacokinetic parameters in rats. $C L_{i n t}$, a parameter of hydrolysis activity of ester prodrugs into the active form, was determined by means of the apical-to-basolateral transcellular transport study in hiPSC-IECs as described in Materials and Methods. The $C L_{\text {int }}$ values of six ester prodrugs (prodrugs $\mathrm{A}, \mathrm{B}, \mathrm{C}, \mathrm{D}, \mathrm{E}$, and $\mathrm{F}$ ) in hiPSC-IECs were compared with the pharmacokinetic parameters (A) $\mathrm{C}_{\max }$, (B) AUC, and (C) $B A$, in rats. These pharmacokinetic parameters of six prodrugs in rats were calculated from the plasma concentrations of the active form after oral administration of six prodrugs and intravenous administration of the active form. Six ester prodrugs and the active form are in-house compounds synthesized by Shionogi \& Co., Ltd., and these six prodrugs are all hydrolyzed into the same active form. Each value of $C L_{\text {int }}$ in hiPSC-IECs represents the mean \pm S.E.M. of three determinations. Each value of $C_{\max }$, AUC, and $B A$ in rat represents the mean of two or three rats.

P-gp, BCRP, and PEPT1 play important roles in intestinal drug absorption. The functions of BCRP and PEPT1 in hiPSC-IECs have been previously reported (Iwao et al., 2015; Ogaki et al., 2015; Ozawa et al., 2015; Kodama et al., 2016; Uchida et al., 2017), whereas the present study is the first to reveal the functional expression of P-gp in hiPSC-IECs. The $P_{a p p}$ value of $\left[{ }^{3} \mathrm{H}\right]$ digoxin (a P-gp substrate) in the basolateral-to-apical direction was greater than that in the apical-tobasolateral one (efflux ratio, 2.43), and the differences in $P_{a p p}$ in these two directions disappeared in the presence of cyclosporin A (efflux ratio, 0.743) (Fig. 3A). The efflux ratio of digoxin in human jejunum on the basis of the Ussing chamber technique was reported to be 5.41 (Sjöberg et al., 2013), and the value was 2.25-fold higher compared with the present study. We found 11.1-fold lower gene expression of P-gp in hiPSC-IECs than in adult human small intestine (Fig. 1), supporting the difference in P-gp activity between hiPSC-IECs and human jejunum. Besides P-gp, the efflux transport of sulfasalazine (a BCRP substrate) and influx transport of $\left[{ }^{14} \mathrm{C}\right]$ glycylsarcosine (a PEPT1 substrate) were reduced by inhibitors of BCRP and PEPT1, indicating that hiPSC-IECs have the transport activities of BCRP and PEPT1 (Fig. 3, B and C). These results showed that hiPSC-IECs can be used to investigate drug absorption of the substrates of P-gp, BCRP, and PEPT1, although gene expression levels of these transporters in hiPSC-IECs were lower than those in adult intestine (Fig. 1).

CYP3A contributes to intestinal first-pass metabolism. Our study of CYP3A4 activity in hiPSC-IECs showed that midazolam was metabolized to 1-OH midazolam, and the metabolizing activity of CYP3A4 was higher in hiPSC-IECs than in Caco-2 cells (Fig. 4A). This reflects the difference in the gene expression of CYP3A4 between hiPSC-IECs and Caco-2 cells (Fig. 1). Since the gene expression level of CYP3A4 was 274-fold lower in hiPSC-IECs than in human small intestine (Fig. 1), the metabolic activity of CYP3A4 in hiPSC-IECs was surmised to be lower than in human small intestine.

In this study, hiPSC-IECs showed lower expression of transporters and metabolic enzymes than human small intestine. A previous report suggested that hiPSC-IECs more closely resemble fetal rather than adult intestine by unsupervised hierarchical clustering of RNA-sequencing data (Finkbeiner et al., 2015). Miki et al. (2005) demonstrated that P-gp and CYP3A4 were more highly expressed in adult than fetal intestine. Taken together, hiPSC-IECs represent immature characteristics. We showed that the gene expression level of CYP3A4 in hiPSC-IECs cultured on Transwell filter for 21 days tended to be higher than that before cultivation on Transwell filter, whereas the expression of CYP3A7, a predominant CYP3A isoform in fetal human small intestine (Shin et al., 2009; Betts et al., 2015), in hiPSC-IECs decreased when cultivated on Transwell filter (Fig. 1). This expression pattern might imply the development of hiPSC-IECs from fetal to adult form. Since the expressions of transporters and metabolic enzymes are still low compared with human small intestine, the culture conditions for further enhancing the degree of maturation and expression of transporters and metabolic enzymes in hiPSC-IECs needs to be clarified.

CES is involved in the hydrolysis of ester prodrugs. There are two major isoforms (CES1 and CES2) in humans, and CES2 is highly expressed in small intestine (Hosokawa, 2008). CES1 is more highly expressed than CES2 in Caco-2 cells (Imai et al., 2005). Since there is a 


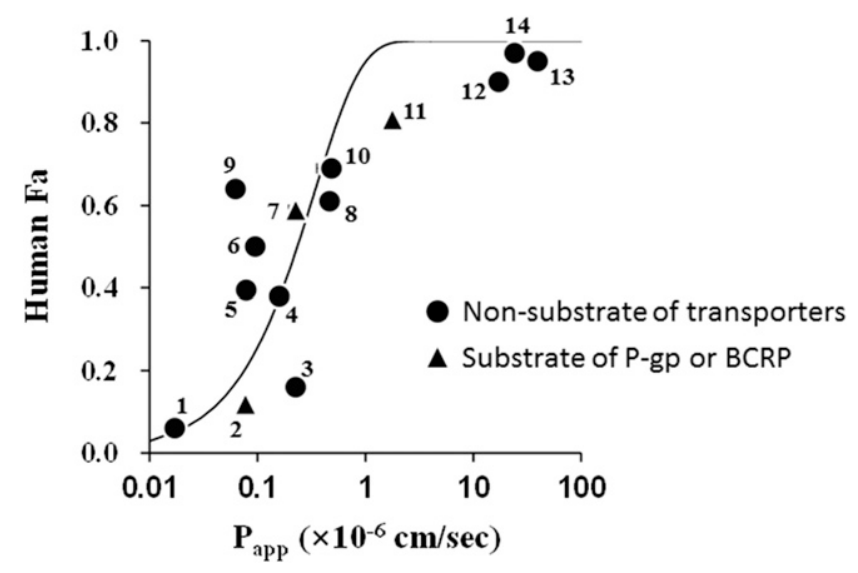

Fig. 6. Comparison of $P_{a p p}$ values of 14 drugs across hiPSC-IEC monolayers with their $F a$ values in humans. The $P_{a p p}$ values of 14 drugs was determined by means of the apical-to-basolateral transcellular transport study across hiPSC-IECs. Ganciclovir, doxorubicin, $\left[{ }^{14} \mathrm{C}\right]$ mannitol, sulfasalazine, and $\left[{ }^{3} \mathrm{H}\right]$ digoxin were set at concentrations of $100,2,10(20 \mu \mathrm{Ci} / \mathrm{ml}), 2$, and $1 \mu \mathrm{M}(1 \mu \mathrm{Ci} / \mathrm{ml})$, respectively, and nine other drugs at $10 \mu \mathrm{M}$. The data for doxorubicin represent the mean of duplicate experiments, and the data for 13 other drugs represent the mean \pm S.E.M. of triplicate experiments. 1, ganciclovir; 2, doxorubicin; 3 , $\left[{ }^{14} \mathrm{C}\right]$ mannitol; 4, famotidine; 5 , sulpiride; 6 , atenolol; 7 , sulfasalazine; 8 , furosemide; 9 , ranitidine; 10 , hydrochlorothiazide; 11, $\left[{ }^{3} \mathrm{H}\right]$ digoxin; 12 , acetaminophen; 13, propranolol; 14 , antipyrine. Circle and triangle symbols represent nonsubstrate of transporters and substrate of P-gp or BCRP. Human $\mathrm{Fa}$ values were taken from the literature (Zhao et al., 2001; Sugano et al., 2002; Varma et al., 2010). If multiple $F a$ values are reported in these publications, the median value was calculated and used. The solid line represents the correlation curve between $P_{a p p}$ values and Human $F a$ values; $F a=\exp \left(-2.96 \times P_{a p p}\right)$.

difference in substrate specificity between CES2 and CES1 (Hosokawa, 2008), the hydrolysis of ester prodrugs in Caco-2 cells does not reflect that in human small intestine. Imai et al. (2005) demonstrated that hydrolysis of temocapril (a substrate of CES1) was not detected in human small intestinal microsomes but was detected in the S9 membrane fraction of Caco-2 cells. Also, Ishiguro et al. (2014) proposed that the intestinal absorption of dabigatran etexilate (a substrate of CES1) was misread using Caco-2 cells owing to overestimation of the contribution of hydrolysis via CES1. In the present study, the expression level of CES2 in hiPSC-IECs was almost equal to that in Caco-2 cells, whereas CES1 was more highly expressed in Caco- 2 cells than hiPSCIECs (Fig. 1). Likewise, the hydrolysis activity of irinotecan (a substrate of CES2) was almost the same as that in Caco-2 cells (Fig. 4B), whereas the hydrolysis activity of temocapril was markedly greater in Caco-2 cells than hiPSC-IECs (Fig. 4C). These results imply that hiPSC-IECs may be a useful model for studying intestinal hydrolysis activity with little influence from CES1-mediated hydrolysis compared with Caco-2 cells.

To examine whether in vivo hydrolysis in small intestine can be investigated using hiPSC-IECs, we compared the hydrolysis of six ester prodrugs in hiPSC-IECs with $C_{\max }$, AUC, and $B A$ of the active form after oral administration to rats. $C L_{i n t}$, a parameter reflecting the hydrolysis rate of a prodrug into its active form, increases as the hydrolysis rate of the prodrug increases. $C L_{i n t}$ values of the six prodrugs in hiPSC-IECs were correlated well with each pharmacokinetic parameter for rats (Fig. 5; Supplemental Table S5). $C L_{i n t}$ of the prodrugs in hiPSC-IECs reflected two processes: permeation of the prodrug into the cells and hydrolysis of the prodrug to its active form in the cells (Supplemental Eq. S1; Supplemental Fig. S4). However, besides these two processes, intestinal absorption of prodrugs includes permeation from the intestinal cells to the portal vein of the active form produced by hydrolysis of prodrugs (Supplemental Eq. S2; Supplemental Fig. S4). Since the six prodrugs used in the present study were all hydrolyzed into a common active form, the permeability of the basolateral efflux of the active form was the same for these prodrugs (Supplemental Eq. S3). Thus, $C L_{i n t}$ values can be correlated with the absorption rate of a prodrug in the intestinal lumen and with intestinal hydrolysis on the basis of pharmacokinetic theory. Although we did not confirm species differences between human and rat small intestine in the hydrolysis activities of these six prodrugs, $C L_{\text {int }}$ of prodrugs in hiPSC-IECs might be useful as an index for in vivo hydrolysis activities in prodrugs derived from a common active form. Further study is needed to clarify whether hydrolysis of prodrugs in hiPSC-IECs also reflects that in human intestine.

Since hiPSC-IECs formed tight junctions and have the function of drug transporters, we compared the $P_{a p p}$ values of 14 drugs in hiPSCIECs with their human $\mathrm{Fa}$ values. These 14 drugs included two P-gp substrates, one BCRP substrate, and 11 nonsubstrates of transporters. The $P_{a p p}$ values of the 14 drugs in hiPEC-IECs were correlated with their human $\mathrm{Fa}$ values (Fig. 6; Supplemental Table S6). This suggested that hiPSC-IECs could predict the oral absorption of drugs in human small intestine by various mechanisms, such as passive diffusion and efflux transport via P-gp and BCRP. According to the previous report (Amidon et al., 1988), theoretical fitting curve was created between the values of $P_{a p p}$ in hiPSC-IECs and human $F a$ of 14 drugs. Since the determination coefficient was high (0.691), it was suggested that the methodology of prediction of human $F a$ values from $P_{a p p}$ of hiPSCIECs was theoretically reasonable. However, predicted human $F a$ values of $\left[{ }^{14} \mathrm{C}\right]$ mannitol and ranitidine showed more than 3-fold differences compared to observed ones (Supplemental Table S6). There is a possibility of the contribution of transporters to intestinal absorption. However, as a result of the parallel artificial membrane permeation assay (PAMPA), which can predict human $\mathrm{Fa}$ of drugs via the passive absorption processes, the predicted and observed $F a$ values of $\left[{ }^{14} \mathrm{C}\right]$ mannitol and ranitidine were relatively consistent (Sugano et al., 2002). This indicated that there is little contribution of transporters to intestinal absorption of $\left[{ }^{14} \mathrm{C}\right]$ mannitol and ranitidine. It will be necessary to conduct further studies to clarify the reason why these drugs are outliers.

In conclusion, we generated hiPSC-IECs that possess crucial factors in drug oral absorption: tight junctions, transporters (P-gp, BCRP, and PEPT1), and metabolic enzymes (CYP3A4, CES2, and CES1). The hydrolysis activities of six ester prodrugs into the active form in hiPSCIECs were correlated with the plasma exposures of the active form after oral administration of these prodrugs in rat. Furthermore, the permeability coefficients of 14 drugs in hiPSC-IECs were also correlated with human $\mathrm{Fa}$ values. Therefore, hiPSC-IECs should be a useful cell model for studying drug absorption in the small intestine. For drugs metabolized in the small intestine, it is important to predict not only $F a$ but also the fraction escaping intestinal extraction $(F g)$. Since the expression of CYP3A4 was much lower in hiPSC-IECs than human small intestine, substrates of CYP3A4 were not used for the prediction of the absorption in vivo. If this expression level of CYP3A4 is increased in the future study, it could be expected to calculate the values of $\mathrm{Fa} \times \mathrm{Fg}$ to accurately predict the oral absorption of the substrates for transporters and/or metabolic enzymes using hiPSC-IECs.

\section{Acknowledgments}

We thank Maki Minaguchi and Sayori Nishio (Shionogi Techno Advance Research Co., Ltd., Toyonaka, Japan) for support with the cultivation of hiPSCs and hiPSC-IECs. We also thank Miho Tachibana and Tomoka Soda (Shionogi Techno Advance Research Co., Ltd.) for support with quantifying the concentrations of compounds using LC-MS/MS

\section{Authorship Contributions}

Participated in research design: Akazawa, Yoshida, Kawai. 
Conducted experiments: Akazawa.

Contributed new reagents or analytic tools: Kawai.

Performed data analysis: Akazawa.

Wrote or contributed to the writing of the manuscript: Akazawa, Ohnishi, Kanazu, Takahashi.

\section{References}

Akazawa T, Uchida Y, Miyauchi E, Tachikawa M, Ohtsuki S, and Terasaki T (2018) High expression of UGT1A1/1A6 in monkey small intestine: comparison of protein expression levels of cytochromes P450, UDP-glucuronosyltransferases, and transporters in small intestine of Cynomolgus monkey and human. Mol Pharm 15:127-140.

Amidon GL, Sinko PJ, and Fleisher D (1988) Estimating human oral fraction dose absorbed: correlation using rat intestinal membrane permeability for passive and carrier-mediated compounds. Pharm Res 5:651-654.

Betts S, Björkhem-Bergman L, Rane A, and Ekström L (2015) Expression of CYP3A4 and CYP3A7 in human foetal tissues and its correlation with nuclear receptors. Basic Clin Pharmacol Toxicol 117:261-266.

Delavenne X, Ollier E, Basset T, Bertoletti L, Accassat S, Garcin A, Laporte S, Zufferey P, and Mismetti P (2013) A semi-mechanistic absorption model to evaluate drug-drug interaction with dabigatran: application with clarithromycin. Br J Clin Pharmacol 76:107-113.

Fenner KS, Troutman MD, Kempshall S, Cook JA, Ware JA, Smith DA, and Lee CA (2009) Drugdrug interactions mediated through P-glycoprotein: clinical relevance and in vitro-in vivo correlation using digoxin as a probe drug. Clin Pharmacol Ther 85:173-181.

Finkbeiner SR, Hill DR, Altheim CH, Dedhia PH, Taylor MJ, Tsai YH, Chin AM, Mahe MM, Watson CL, Freeman JJ, et al. (2015) Transcriptome-wide analysis reveals hallmarks of human intestine development and maturation in vitro and in vivo. Stem Cell Reports DOI: 10.1016/j. stemcr.2015.04.010 [published ahead of print].

Fisher JM, Wrighton SA, Watkins PB, Schmiedlin-Ren P, Calamia JC, Shen DD, Kunze KL, and Thummel KE (1999) First-pass midazolam metabolism catalyzed by 1alpha,25-dihydroxy vitamin D3-modified Caco-2 cell monolayers. J Pharmacol Exp Ther 289:1134-1142.

Forbester JL, Goulding D, Vallier L, Hannan N, Hale C, Pickard D, Mukhopadhyay S, and Dougan G (2015) Interaction of Salmonella enterica Serovar Typhimurium with intestinal organoids derived from human induced pluripotent stem cells. Infect Immun 83:2926-2934.

Gröer C, Busch D, Patrzyk M, Beyer K, Busemann A, Heidecke CD, Drozdzik M, Siegmund W, and Oswald S (2014) Absolute protein quantification of clinically relevant cytochrome P450 enzymes and UDP-glucuronosyltransferases by mass spectrometry-based targeted proteomics. J Pharm Biomed Anal 100:393-401

Hanioka N, Ozawa S, Jinno H, Ando M, Saito Y, and Sawada J (2001) Human liver UDPglucuronosyltransferase isoforms involved in the glucuronidation of 7-ethyl-10-hydroxycamptothecin. Xenobiotica 31:687-699.

Hosokawa M (2008) Structure and catalytic properties of carboxylesterase isozymes involved in metabolic activation of prodrugs. Molecules 13:412-431.

Humerickhouse R, Lohrbach K, Li L, Bosron WF, and Dolan ME (2000) Characterization of CPT11 hydrolysis by human liver carboxylesterase isoforms hCE-1 and hCE-2. Cancer Res $\mathbf{6 0}$ : $1189-1192$.

Imai T, Imoto M, Sakamoto H, and Hashimoto M (2005) Identification of esterases expressed in Caco-2 cells and effects of their hydrolyzing activity in predicting human intestinal absorption. Drug Metab Dispos 33:1185-1190.

Ishiguro N, Kishimoto W, Volz A, Ludwig-Schwellinger E, Ebner T, and Schaefer O (2014) Impact of endogenous esterase activity on in vitro p-glycoprotein profiling of dabigatran etexilate in Caco-2 monolayers. Drug Metab Dispos 42:250-256.

Iwao T, Kodama N, Kondo Y, Kabeya T, Nakamura K, Horikawa T, Niwa T, Kurose K, and Matsunaga T (2015) Generation of enterocyte-like cells with pharmacokinetic functions from human induced pluripotent stem cells using small-molecule compounds. Drug Metab Dispos 43:603-610

Kabeya T, Matsumura W, Iwao T, Hosokawa M, and Matsunaga T (2017) Functional analysis of carboxylesterase in human induced pluripotent stem cell-derived enterocytes. Biochem Biophys Res Commun 486:143-148.

Kauffman AL, Gyurdieva AV, Mabus JR, Ferguson C, Yan Z, and Hornby PJ (2013) Alternative functional in vitro models of human intestinal epithelia. Front Pharmacol 4:79.

Keskitalo JE, Zolk O, Fromm MF, Kurkinen KJ, Neuvonen PJ, and Niemi M (2009) ABCG2 polymorphism markedly affects the pharmacokinetics of atorvastatin and rosuvastatin. Clin Pharmacol Ther 86:197-203.

Kim JE, Cho HJ, Kim JS, Shim CK, Chung SJ, Oak MH, Yoon IS, and Kim DD (2013) The limited intestinal absorption via paracellular pathway is responsible for the low oral bioavailability of doxorubicin. Xenobiotica 43:579-591.

Kodama N, Iwao T, Katano T, Ohta K, Yuasa H, and Matsunaga T (2016) Characteristic analysis of intestinal transport in enterocyte-like cells differentiated from human induced pluripotent stem cells. Drug Metab Dispos 44:0.

Kusuhara H, Furuie H, Inano A, Sunagawa A, Yamada S, Wu C, Fukizawa S, Morimoto N, Ieiri I, Morishita M, et al. (2012) Pharmacokinetic interaction study of sulphasalazine in healthy subjects and the impact of curcumin as an in vivo inhibitor of BCRP. $\mathrm{Br} J$ Pharmacol 166: $1793-1803$.
Liang E, Proudfoot J, and Yazdanian M (2000) Mechanisms of transport and structure-permeability relationship of sulfasalazine and its analogs in Caco-2 cell monolayers. Pharm Res 17: $1168-1174$.

Miki Y, Suzuki T, Tazawa C, Blumberg B, and Sasano H (2005) Steroid and xenobiotic receptor (SXR), cytochrome P450 3A4 and multidrug resistance gene 1 in human adult and fetal tissues. Mol Cell Endocrinol 231:75-85.

Miyauchi E, Tachikawa M, Declèves X, Uchida Y, Bouillot JL, Poitou C, Oppert JM, Mouly S, Bergmann JF, Terasaki T, et al. (2016) Quantitative atlas of cytochrome P450, UDPglucuronosyltransferase, and transporter proteins in jejunum of morbidly obese subjects. Mo Pharm 13:2631-2640.

Ogaki S, Morooka M, Otera K, and Kume S (2015) A cost-effective system for differentiation of intestinal epithelium from human induced pluripotent stem cells. Sci Rep 5:17297.

Ogaki S, Shiraki N, Kume K, and Kume S (2013) Wnt and Notch signals guide embryonic stem cell differentiation into the intestinal lineages. Stem Cells 31:1086-1096.

Ozawa T, Takayama K, Okamoto R, Negoro R, Sakurai F, Tachibana M, Kawabata K, and Mizuguchi H (2015) Generation of enterocyte-like cells from human induced pluripotent stem cells for drug absorption and metabolism studies in human small intestine. Sci Rep 5:16479.

Paine MF, Hart HL, Ludington SS, Haining RL, Rettie AE, and Zeldin DC (2006) The human intestinal cytochrome P450 "pie". Drug Metab Dispos 34:880-886.

Paine MF, Shen DD, Kunze KL, Perkins JD, Marsh CL, McVicar JP, Barr DM, Gillies BS, and Thummel KE (1996) First-pass metabolism of midazolam by the human intestine. Clin Pharmacol Ther 60:14-24.

Prueksaritanont T, Gorham LM, Hochman JH, Tran LO, and Vyas KP (1996) Comparative studies of drug-metabolizing enzymes in dog, monkey, and human small intestines, and in Caco-2 cells. Drug Metab Dispos 24:634-642.

Rashid TJ, Martin U, Clarke H, Waller DG, Renwick AG, and George CF (1995) Factors affecting the absolute bioavailability of nifedipine. Br J Clin Pharmacol 40:51-58.

Rubio-Aliaga I and Daniel H (2008) Peptide transporters and their roles in physiological processes and drug disposition. Xenobiotica 38:1022-1042.

Sato T, Stange DE, Ferrante M, Vries RG, Van Es JH, Van den Brink S, Van Houdt WJ, Pronk A, Van Gorp J, Siersema PD, et al. (2011) Long-term expansion of epithelial organoids from human colon, adenoma, adenocarcinoma, and Barrett's epithelium. Gastroenterology 141:1762-1772.

Shin HC, Kim HR, Cho HJ, Yi H, Cho SM, Lee DG, Abd El-Aty AM, Kim JS, Sun D, and Amidon GL (2009) Comparative gene expression of intestinal metabolizing enzymes. Biopharm Drug Dispos 30:411-421.

Simpson K and Jarvis B (2000) Fexofenadine: a review of its use in the management of seasonal allergic rhinitis and chronic idiopathic urticaria. Drugs 59:301-321.

Sjöberg Å, Lutz M, Tannergren C, Wingolf C, Borde A, and Ungell AL (2013) Comprehensive study on regional human intestinal permeability and prediction of fraction absorbed of drugs using the Ussing chamber technique. Eur J Pharm Sci 48:166-180.

Spence JR, Mayhew CN, Rankin SA, Kuhar MF, Vallance JE, Tolle K, Hoskins EE, Kalinichenko VV, Wells SI, Zorn AM, et al. (2011) Directed differentiation of human pluripotent stem cells into intestinal tissue in vitro. Nature 470:105-109.

Sugano K, Takata N, Machida M, Saitoh K, and Terada K (2002) Prediction of passive intestinal absorption using bio-mimetic artificial membrane permeation assay and the paracellular pathway model. Int J Pharm 241:241-251.

Taipalensuu J, Törnblom H, Lindberg G, Einarsson C, Sjöqvist F, Melhus H, Garberg P, Sjöström $\mathrm{B}$, Lundgren B, and Artursson P (2001) Correlation of gene expression of ten drug efflux proteins of the ATP-binding cassette transporter family in normal human jejunum and in human intestinal epithelial Caco-2 cell monolayers. J Pharmacol Exp Ther 299:164-170.

Takayama N, Nishimura S, Nakamura S, Shimizu T, Ohnishi R, Endo H, Yamaguchi T, Otsu M, Nishimura K, Nakanishi M, et al. (2010) Transient activation of c-MYC expression is critical for efficient platelet generation from human induced pluripotent stem cells. J Exp Med 207: 2817-2830.

Tapaninen T, Backman JT, Kurkinen KJ, Neuvonen PJ, and Niemi M (2011) Itraconazole, a P-glycoprotein and CYP3A4 inhibitor, markedly raises the plasma concentrations and enhances the renin-inhibiting effect of aliskiren. J Clin Pharmacol 51:359-367.

Troutman MD and Thakker DR (2003) Efflux ratio cannot assess P-glycoprotein-mediated attenuation of absorptive transport: asymmetric effect of P-glycoprotein on absorptive and secretory transport across Caco-2 cell monolayers. Pharm Res 20:1200-1209.

Uchida H, Machida M, Miura T, Kawasaki T, Okazaki T, Sasaki K, Sakamoto S, Ohuchi N, Kasahara M, Umezawa A, et al. (2017) A xenogeneic-free system generating functional human gut organoids from pluripotent stem cells. JCI Insight 2:e86492.

Varma MV, Obach RS, Rotter C, Miller HR, Chang G, Steyn SJ, El-Kattan A, and Troutman MD (2010) Physicochemical space for optimum oral bioavailability: contribution of human intestinal absorption and first-pass elimination. J Med Chem 53:1098-1108.

Zhao YH, Le J, Abraham MH, Hersey A, Eddershaw PJ, Luscombe CN, Butina D, Beck G, Sherborne B, Cooper I, et al. (2001) Evaluation of human intestinal absorption data and subsequent derivation of a quantitative structure-activity relationship (QSAR) with the Abraham descriptors [published correction appears in J Pharm Sci (2002) 91:605]. J Pharm Sci 90:749-784.

Address correspondence to: Dr. Takanori Akazawa, Research Laboratory for Development, Shionogi \& Co., Ltd., 3-1-1, Futaba-cho, Toyonaka, Osaka 5610825, Japan. E-mail: takanori.akazawa@shionogi.co.jp 